\title{
Theory, Activism, and the Other Ways An Interview with Carol J. Adams
}

\section{Adele Tiengo}

$\mathrm{PhD}$, Student in Foreign Languages and Literature at the University of Milan, Italy

doi: 10.7358/rela-2013-001-tien

adele.tiengo@unimi.it

Carol Adams, writer, activist, feminist vegan, is the author of the The Sexual Politics of Meat (1990). In more than 20 years, her most famous and innovative work has reached a wider and wider readership, being translated into many languages (Japanese, Korean, Chinese, German, and Portuguese). She authored and edited several books and essays, like Animals and Women: Feminist Theoretical Exploration (1995) and The Feminist Care Tradition in Animal Ethics: a Reader (2007), both edited with Josephine Donovan, and Living Among Meat Eaters: the Vegetarian's Survival Handbook (2003). As an activist, she worked particularly - but not exclusively - on domestic violence and racism.

While I was doing research on ecofeminism and the interrelation between the exploitation of women and animals, I contacted her with the hope of gaining a deeper understanding of these themes. I was particularly interested in the different roles that images and texts hold in Western culture and their influence on meat-eating, in approaches to animal exploitation as diverse as activism and literature, and in the relation between veganism and other kinds of food activism. We had a very warm and friendly voip conversation, in which she helpfully answered to my questions and doubts.

I think that her contribution is relevant to the subject of the emotional lives of animals, with a specific focus on human animals. In books like Living Among Meat Eaters, Carol Adams has given great attention to the interactions between vegans and meat-eaters, since this interaction involves emotionally both categories and indirectly concerns the lives of nonhuman animals. In explaining her engagement in feminist-vegan activism, she underlined how issues such as racism, sexism, and speciesism cannot be addressed in a merely rationalized way. More than perfectly consistent philosophical arguments, it is strategic non-verbal language that makes people move from their positions. In a way, it is the exposition of emo-

Relations - 1.I - June 2013

http://www.ledonline.it/Relations/ 
tional involvement of human and nonhuman animals (as it is conveyed by, for example, literary works) that leads the way towards a change of heart.

AT: I would like to start from the beginning. In the preface to the $10^{\text {th }}$ anniversary edition of The Sexual Politics of Meat you write that you had been thinking about it for 15 years. In the preface to the $20^{\text {th }}$ anniversary edition, you reassert the pathway of activism that led you to write your engaged theory. Does this mean the time was not ripe for you to write it or for the public to read it? Did you need more activist engagement before writing theory?

CA: When I first had the idea in 1974, I wrote it as a paper and the following year somebody suggested I turn it into a book. So I started writing it but after writing about 200 pages, it felt very linear and flat. It seemed that all I was saying was "look at this example; now look at this other example: they are connected!" or "look at how men are the ones who fight the wars and look at how men are the ones who slaughter the animals: this is connected". I knew my argument needed to be stronger and more convincing than simply saying, "there are connections".

I also had to learn how to write this kind of book. At first my thinking was like "oh look, Mary Shelley makes the monster a vegetarian! Isn't that interesting? And Percy Shelley wrote A Vindication of Natural Diet, taking the title from The Vindication of the Rights of Women, written by Mary Shelley's mother! So, look at all that!". But still it felt very linear, dualistic. It seemed as though there was a deeper level to get at about the connections.

What I realized was that I needed more time to think it through. I sensed that I probably only had one chance to get people to read me and I didn't want something that I thought was inadequate to represent my ideas. So, I needed to put it aside to figure out "what's really going on now?". It's not enough to say, "look at this, and look at that", I needed to have a theory that explained why these connections existed.

I think the other thing is that I wasn't ever really interested in going to graduate school per se. I didn't see myself as a professor; I didn't see how the kind of work I was doing was something you can do in graduate school. In Species Matters, an anthology from Columbia, I have a chapter called "What Came Before the Sexual Politics of Meat" and I talk very specifically about my activism in the 1980s. I learned several things from this activism that was crucial to completing The Sexual Politics of Meat. First of all I learned all the skills of activism that you can only learn by being an activist: I learned how to be articulate under pressure, how to take a 
stance and how to think through strategy, how to follow through toward a realistic and urgent goal. I also learned how to write - to organize thoughts and develop arguments because as an activist I was writing a challenge to the license of a radio station, I was writing grants for a domestic violence hotline, I was learning how to write fast and accurately. I was also reading a lot. It was a very tense time; there were a lot of personal attacks on my partner and me for our work against racism and for integrated housing. During this time, I was doing the research that was moving me towards my feminist-veg theory.

I guess the other thing that activism did was that it allowed me to think about how ideas are experienced by others. Those ideas can be threatening, and how do you respond when someone feels threatened? I see that now with the issue of veganism. We think we have to argue with non-vegans, we think we have to be very precise, logocentric, but what I realized through activism is that you can have the best arguments in the world and that's not going to get a racist to change their beliefs! They are not going to move off their position because they are scared; in settling for argumentation rather than other strategic interventions, many of which are non-verbal, we may contribute to the status quo rather than challenge it.

It's not that I decided I needed to be an activist before writing theory. I had to be an activist because I believed in the importance of activism of siding with the non-dominant - and then, as a result, activism became the pathway to returning to the writing of the book with deeper levels of understanding about what was going on.

By fighting against racism I was seeing all the racist permutations of looking at African-American people as less than human (the process of animalizing people of color) and I realized that it's not something theoretical, but something you are engaged with at a very activist level. I took my activism and examined it theoretically as a very dynamic thing. Again, it's not that I was going to be an activist so I could write better, but I needed to be an activist. Additionally, I didn't know what to do with all those ideas! But I did know what I wanted to do around domestic violence and around racism and I needed to be doing something there: to be silent in the 1970s around these issues was untenable and in gaining that voice it turned out I could gain the other, the theoretical voice. But if you ask me if this was the plan, it was not a plan!

AT: The German philosopher Max Horkheimer writes that the capitalist skyscraper of human exploitation is grounded in animal exploitation, that the basement of this skyscraper is a slaughterhouse. You subtitle your book "a feminist-vegetarian critical theory": what are the connections, if any, 
between animal rights and the Frankfurt school and Horkheimer's critical theory?

CA: I wasn't that familiar with his theory when I wrote The Sexual Politics of Meat. Certainly, if you look at exploitation, in The Sexual Politics of Meat I talked about how the word 'capital' is related to cattle. I also look at how Ford was inspired to create the factory assembly line by watching the slaughterhouse routines in Chicago. Barbara Noske begins her book Humans and Other Animals by talking about animals as examples of alienated labor. Animals as alienated laborers are alienated from their own bodies, in the first chapter she explains that they are the producers of their own bodies as the product.

She calls this the Animal Industrial Complex, like the military industrial complex. Many people have argued that all oppressions are built on the oppression of animals and that the model for women's oppression is the domestication of farm animals. As Noske said, meat is an appropriate food for capitalism; you always need more raw material because you are losing up lots of the raw material in the production of the meat.

I think one of my interventions is to say "we have to be looking at what is happening with gender" and how animals are gendered (feminized and sexualized), and how women and other non-dominant people are animalized. I think that the feminist-vegan theory and, for example, the Frankfurt school intersect and that there's much more work that can be done.

AT: In The Sexual Politics of Meat you developed a theory that owes much to literature. How can literary criticism work in the direction of animal advocacy?

CA: Fiction opens new worlds for readers. I like to think that fiction helps us encounter the other animals in non-dominant ways. Literary criticism, at its best, helps us become involved readers, introduces us to new ways of thinking about literature, and challenges us.

For me literary criticism was both a model and provided theoretical insights. Through literary criticism, I discovered the literary concept of the absent referent and suddenly realized that this was what the animals are, this is how animals disappear. Through literary criticism, I realized I should address the issue of how vegetarianism appears in a novel, not just that it appears. So I identified the operating of the narrative technique of 'interruption'. Interruption occurs in a novel when the narration is interrupted by issues related to vegetarianism; the interruption gives the opportunity to stop and think about the ideas being introduced. 
There was no model for what I was doing. As with the idea of "interruption" in novels, sometimes I just had to make it up.

I am concerned that as animal studies becomes trendy, we'll encounter literary criticism that talks about animals but keeps them as absent referents; that is, keeps them safely untouched (and unprotected) by human hands or only touched in the literary sphere without a reflection on real life. I am referring to scholars who write about animals and yet eat dead animals. In their writings have they encountered animals in non-dominant ways if they continue to engage in dominant and oppressive activities against animals in their lives? In academia, animals have suddenly become a whole newly discovered but yet uncovered field: "animals in Shakespeare", "animals in Auden", "animals in Jane Austen".

I was never looking at what was happening to animals only because it said something about a novel: I wanted to look at what was happening to animals in novels because I thought the novel told us something about what was happening to living and breathing animals.

I think literary criticism is always politicized, somebody is eating someone - or not - after they stop reading a novel. And someone is eating someone - or not - after writing literary criticism. The importance to me is getting to 'not'.

AT: For example, in The Lives of Animals John Maxwell Coetzee displays an opposition between philosophy and literature, and between rationality and sympathetic imagination. What do you think about this opposition? What kind of approach is more appropriate?

CA: Let's look at who Coetzee creates to represent a point of view about the other animals. He creates a woman who is 62 or 63 , he embodies the tensions that he wants to talk about in a woman who is (supposedly) aged and we know that because he is showing this from the perspective of her son. The first thing that the son acknowledges is that she is aging and he is uncomfortable with her aging body. At the center of the novel is not just a woman writer, but a woman writer with a body that is mediated through the eyes of younger man. The uncomfortable conversation with her daughter-in-law (and the way she can't eat with her grandchildren - most inhospitable!), I think, reveals a very interesting aspect about the issue I call Living Among Meat Eaters. In a journal essay, Coetzee writes about the time when he was teaching at the University of Texas and he was invited to a barbecue, where there was nothing that he could eat. Part of The Lives of Animals raises the issue of relationships between vegetarians/vegans and non-vegans and the difficulties encountered. 
In The Feminist Care Tradition in Animal Ethics, Josephine Donovan and I claim Coetzee as part of the feminist ethics of care; we argue that Coetzee's work falls into that category. (We boldly claim Derrida, too!). In a dialogue with Paola Cavalieri he says that people have a sort of a revelation about the animals and then they go back and look for a rational justification. But before rationality, there is this revelation of embodiment. When he creates any kind of opposition or tension in The Lives of Animals, I think, he is pushing us to recognize that bow we feel is working at a level that we might not be talking about or acknowledging, but that these feelings may be influencing everything. So, of course, he is creating an opposition between philosophy and literature at the level of the reading, but at the level of the writing he isn't, because it was the sympathetic imagination that was authoring the tension. It's the sympathetic imagination that can engage with all of these issues in such an intelligent and fascinating way.

AT: Another literary approach to the industrial exploitation of nonhuman animals comes from novelist Ruth Ozeki. While writing her novel My Year of Meats, she discovers that women are not only metaphorically treated like cows, but they were being given the identical drug - Diethylstilbestrol (DES). What do you think about this dramatic connection?

CA: Many people said to me she must have read The Sexual Politics of Meat, the issues of the sexual politics of meat appear in many chapters and I think it's a lovely book, a sad book, but also a very well written book. It's not just that women, like cows, were given the identical drug. There is so much more: the reproductive technologies created for women were created based on the reproductive manipulation of cows, because cows are in sexual slavery, because cows have to reproduce all the time, and so they need the hormones. I think My Year of Meats shows many other feminist issues in meat eating, as well.

AT: Skimming through The Sexual Politics of Meat, it seems that while written texts foster both positive and negative ideas about women and animals, all advertising and visual images are disturbing, anti-feminist, and speciesist. Is there something right in this impression? Is visual language more violent and oppressive than verbal language? Does it have something to do with pornography?

CA: I think there's something right about that. John Berger's Ways of Seeing says that "men look at women and women look at men looking at women". We are being experienced and being looked at and this reflects 
that attitude in Western philosophy that held that women are closer to the body and men are closer to the rational. So many responses to animals follow that dualism and, apart from the ads, we have this attitude that is always placing women as separate from men. The sexual politics of meat is about living beings who become consumable, visually consumable women or literally consumable domesticated and hunted animals.

Yes, I think that visual language is more violent and potentially more oppressive than verbal language. There is a beautiful book, The Pornography of Representation by Susanne Kappeler that links the problem of 'looking' with subjectification. 'Looking' in Western culture means a subject looking at an object, at the expense of another being who becomes that object. 'Looking' is something that instantiates dominance for the viewer. So, a hierarchy is automatically instantiated in looking, but not in reading.

AT: Last year, you have criticized a new video released by People for the Ethical Treatment of Animals (PETA) - one of the most popular organizations of animal advocacy -, which is meant to oppose the idea that (male) vegans are not sexually healthy and virile. The video shows a girl suffering from the consequences of violent sexual intercourse with her vegan boyfriend and seems to be ironic about sexual and domestic violence. Can you explain your point of view on this subject?

CA: PETA would never criticize the functioning of the sexual politics of meat in society; it needs it. PETA uses the sexual politics of meat to make its way into the dominant culture. PETA is very clever; they know what gets attention. Sex sells. I think PETA is misogynist and even women (like some of the people making decisions at PETA) can be misogynist. They know that what they sell as an idea or topic or video is not restoring the absent referent, they concede that our culture does not care about animals, and so they are always not so much representing animals as letting something else represent their message. And one way that they have chosen to supposedly represent the concerns of animals is by using women's bodies.

Our culture rewards PETA for being misogynist by giving it attention when it does misogynistic things. Our culture knows how to talk about women as objects, knows how to look at women as objects. The idea that you have to reassure men about their sexuality because they have become vegan is absurd. Why would you engage in the discussion at that level? It seems much more $19^{\text {th }}$ century, instead of $21^{\text {st }}$ century.

The problem is that PETA monopolizes the small amount of attention allowed for animal rights activism by the dominant culture, and their monopoly involves sexualizing that space. One of the effects is that women 
animal activists all around the world trying to get attention for their cause are ignored because they are not presenting it in a sexy or sexualized way. So PETA changes the environment for what is being deemed worthy of media attention for all animal activists and I think this is very dangerous and shameful.

AT: In The Sexual Politics of Meat you explain that the food industry exploits mainly nonhuman adult females and babies. However, hunting and other sports like bullfighting usually involve male animals. How would you comment on this?

CA: In chapter 3 of The Sexual Politics of Meat I show that even with hunting there is a tradition of identifying the prey with femaleness. (Defeated animals are seen as "lesser powers" and thus female-like). The cows are seen as so cow-like, dumb, and stupid, and this contributes to the fact that we don't care about eating them. In terms of hunting, it doesn't always involve male animals (it depends upon who is being hunted), but there's certainly a sexual politics of meat around hunting: masculinity is gained through the defeated foe who in defeat is described as female.

The domesticated food industry works in such a way that, whether the animals being consumed are female or not, they are presented as female. American culture, for example, has an obsession for turkey breast and we grow these poor turkeys with breasts that are so big that they can barely bear their weight. So this has to do with how we feminize domesticated animals: it is not that the food industry does not harm male animals, it does! Male chicks are thrown out, because they are not going to become layers. Veal calves, who can't bring more baby calves into the world, are killed too, because what the food industry needs is sexual slavery. What masculine sports need is a regressive reincorporation of manliness and masculinity through harming other animals, so I think that there is a connection.

AT: The American culture is often seen as a meat culture. The cowboy is a typical national figure and rodeo is the official sport in many states. Why are these associations so strong and how does traditional culture influence would-be-vegetarians?

CA: Because of the sexual politics of meat! Because American culture democratizes meat eating and there was already an association of meat with manliness and with imperialism. The idea that men need the strength from dead animals is, to begin with, ironic, since those animals were mainly herbivores, themselves. 
Masculine-defined activities provide continuous rewards for men, which is also interesting. One's maleness is constantly being propped up, which suggests that these ways of inscribing gender are shaky to begin with.

The dominant culture works also conveying what it sees as a negative association between eating vegan or vegetarian with "sissiness", or "being effeminate" or other derogatory statements that imply that a man is less manly if he doesn't eat meat.

One way in which traditions influence would-be-vegetarians is that families reproduce traditional culture and it takes a while for them to learn how to do something differently. It seems to these families that vegetarians are going to destroy everything about family traditions. I did a book called Living Among Meat Eaters that tries to show that you can help your family to discover that you're not going to destroy them just because you're a vegetarian.

AT: For example, Thanksgiving Day is widely associated with the image of a great family dinner with the turkey served as the main dish. How does a vegan come to terms with cultural traditions like this, involving familiar bonds and conviviality as well as cruelty?

CA: Some vegans just keep going to Thanksgiving dinners, other vegans figure out different ways and sometimes they are very lucky and their families decide to have vegan Thanksgiving. I still believe what I wrote in Living Among Meat Eaters, that our presence among meat eaters when they are eating dead animals makes them aware that they are doing something that their own conscience knows is wrong. Our role should be to stay out of the way of the fight that's going on within that person about his own conscience.

AT: The United States have warmly welcomed the Italian-based movement of Slow Food, which fosters an ethical reflection about food consumption encouraging people to care about the environment, their health, and culinary local traditions, but paying very little attention to animals themselves. What do you think about locavorism and the industry of organic meat?

CA: I think locavorism is very dangerous when it fetishizes organic local meat. Locavore 'meat' cannot possibly meet the consumption desires of the entire USA population. I think the idea of organic meat is an avoidance of the fact that we don't need to eat animals. Rather than explore all of the wonderful, varied, creative ways of preparing vegan meals, the response has been to try to 'reform' a bad system, that cannot actually be repaired.

Relations - 1.I - June 2013

http://www.ledonline.it/Relations/ 
It also implies that the problem isn't the killing of animals. I believe the problem is the killing of animals.

One of the results of choosing organic meat and organic milk is that when a cow gets ill in an organic farm she is more likely to be killed because they don't want to use antibiotics. The animals remain means to an end. 'Friendly murder' is still murder.

Veganism started as a political movement and, before we could truly articulate our connections with the food justice movement, locavorism erupted as a safer way of thinking about the world because you don't have to disturb your relationship with other animals and you can still believe that you are being kind. I think that the popularity of locavorism has created a groundswell for dangerous rituals and beliefs. For example, it has also introduced the idea that you can raise hens in your backyard, but people fail to realize that it's more complicated than they understood: where do people get the eggs for those hens? They are getting them from factory farms! So the whole thing is inconsistent, especially when we know that going vegan one day a week is a more effective way of helping the environment than eating local seven days a week.

AT: Recent ecofeminist trends led to researches in posthumanism and trans-corporeality. What do you think about this approach? Do you think that it provides a solid theoretical basis for animal advocacy?

CA: What I've noticed is that there are posthumanist trends trying to label the kind of ecofeminism that I have been writing as essentialist and I see that as lazy and incorrect scholarship. I think that there has been dishonesty in some writers who find it so much easier to cast this earlier stage of ecofeminist writing as just having retrograde views about gender rather than to really engage with us. There is at least one writer who does it to pave the way to justify organic meat, so I have problems with that.

I think there are many interesting dialogues to have about posthumanism. There are many people that are doing very great and exciting work and some others who might find it a safe place to avoid engagement with animals.

AT: As an activist, which are your objectives and how do you pursue them?

CA: Right now, I think of myself as a cultural worker, I'm trying to help people critique the dominant culture, see the world differently, see relationships and possibilities differently, so my objectives could be as simple as getting more people educated about vegan food and introducing people to vegan eating. It could be showing The Sexual Politics of Meat Slide Show 
and trying to reach out to a group and educate them and teach others how to bring critical consciousness to the world we live in. I also work to protect women's reproductive rights, especially in the USA. I'm involved with a group that works with the homeless, and right now, we are also working on a gun buy back.

I think my writing is part of my activism at this point, so on different days I'm doing different things to try to write about change.

AT: What are you working on now?

CA: I'm working with Lori Gruen to edit the papers that were presented at the conference we organized in November 2012 in memory of Marti Kheel. That conference, Finding a Niche for All Animals, involved both established and emerging ecofeminist writers. It was so exciting and a wonderful weekend, although, we were all sad as we remembered Marti and her great work, but also grateful that her life had prompted the conference. 